\title{
O PRINCÍPIO DA SUBSIDIARIEDADE E SUA RELAÇÃO COM A APA DO MUNICÍPIO DE ILHA COMPRIDA, SP
}

\author{
VALESCA CAMARGOS DOS SANTOS ${ }^{1}$ \\ Universidade Estadual de Campinas
}

\begin{abstract}
Resumo: Ilha Comprida é um município que foi transformado em APA (Área de Proteção Ambiental) na década de 1980, pelo governo do Estado de São Paulo. A região onde essa ilha está localizada é muito rica em biodiversidade e também em modos de vida tradicionais, pela existência de algumas comunidades de pescadores caiçaras. As diferentes esferas de poder que atuam em Ilha Comprida, dentro do Princípio da Subsidiariedade, não seguem nessa direção, o que causa muitos conflitos de interesses. Quem sofre com a situação são os moradores, especialmente os caiçaras, que veem seu modo de vida intensamente alterado, nem sempre de maneira positiva, por essa condição.
\end{abstract}

Palavras-chave: Ilha Comprida; Comunidades Caiçaras; APA; Princípio da Subsidiariedade.

\section{PRINCIPLE OF SUBSIDIARITY AND ITS RELATIONSHIP WITH APA OF ILHA COMPRIDA, SP}

Abstract: Ilha Comprida is a city that was transformed into an APA (Environmental Protection Area) in the 1980s by the government of São Paulo. The region where this island is located is very rich in biodiversity and in traditional human life by the existence of some caiçara communities. The different levels of power that operate in Ilha Comprida, inside the principle of subsidiarity, do not follow the same direction, causing many conflicts of interests. Those who suffer from this situation are its inhabitants, especially the caiçaras, who see their lives profoundly changed by this condition, not always in a positive way.

Keywords: Ilha Comprida; Caiçaras Communities; APA; Principle of Subsidiary.

\section{Introdução}

Segundo o Princípio da Subsidiariedade, existem escalas de poder, iniciando no plano mais inferior e se dirigindo até o superior, ou seja, do local até o mais alto,

\footnotetext{
${ }^{1}$ Professora do Estado de Minas Gerais; mestre em Geografia pela Unicamp; especialista em Geografia e Gestão do Território e licenciada em Geografia, ambas pela UFJF; e bacharel em Geografia pela Unesp/Rio Claro. Contato: valescarevistas@gmail.com.
} 
que vai depender da escala utilizada. O poder representado pelo Estado deve permitir a manutenção dos diferentes modos de vida das populações, que muitas vezes são exercidos de forma tradicional, assim como a participação nas decisões políticas que interfiram direta ou indiretamente em suas vidas. Ao Estado, portanto, fica a responsabilidade de exercer as atividades que as comunidades menores precisam ou não conseguem realizar sozinhas de maneira eficaz, mas sem nunca perder de vista o envolvimento dessas comunidades em todas as deliberações.

Ilha Comprida, município localizado no litoral sul do estado de São Paulo, possui uma grande variedade ecossistêmica em sua área e uma história política bastante recente. Antes da sua emancipação política, Ilha Comprida, que primeiro pertenceu a Cananéia e Iguape, já havia sido transformada em uma Unidade de Conservação por apresentar grande riqueza ambiental expressa por um mosaico de diferentes ecossistemas, como manguezais e ambientes de dunas, mas também pelas comunidades de pescadores tradicionais, denominadas caiçaras, e por seu valioso patrimônio cultural, como as áreas de sambaquis. A legislação da APA (Área de Proteção Ambiental), em que foi transformada a Ilha Comprida, não consegue abarcar todas as suas atribuições jurídicas, o que torna este mecanismo legal de conservação e proteção bem aquém da finalidade original.

Sob o viés do Princípio da Subsidiariedade, Ilha Comprida possui as lideranças caiçaras locais, a prefeitura municipal e a gestão da APA, atribuição do governo do Estado de São Paulo que fica situada no município vizinho, Cananéia. Essas entidades, por vezes, não falam a mesma língua e interpretam um contexto legal de maneiras diferentes, complicando a prática dos modos de vida tradicionais na ilha e interferindo no processo de urbanização. $O$ fato de ser muito recente a criação do município também contribui para que haja certa fragilidade nessas relações e, para que elas se estabeleçam e fortaleçam, ainda será necessário tempo.

Este artigo tem como objetivo analisar a maneira pela qual o Princípio da Subsidiariedade acontece na prática e de que formas as comunidades menores são afetadas por ele, ou seja, como a sobreposição de poderes se dá efetivamente na vida de populações de pequenos núcleos. Para tanto, utilizou-se Ilha Comprida como exemplo desse processo.

A metodologia utilizada foi um vasto levantamento bibliográfico acerca do tema abordado e, posteriormente, uma visita de campo realizada para conhecimento da área, com ida às comunidades caiçaras do município de Ilha Comprida. Esta ida a campo visou explorar o município e conversar de maneira informal com alguns moradores de núcleos caiçaras a fim de ouvir deles como se configurava o seu modo de vida e como este vem se transformando a partir da influência da criação das unidades de conservação. A posteriori, todo o material obtido foi analisado para, então, produzir artigos científicos. 


\section{O Princípio da Subsidiariedade}

Esse princípio estabelece as hierarquias de poder, ou seja, ele parte do nível mais baixo de poder, que pode ser o local, e se desloca para cima até atingir o nível mais alto, que pode ser o internacional. A ideia básica da subsidiariedade descende da Igreja Católica, é permeada pelo pensamento grego da Idade Média e busca o equilíbrio na divisão das atribuições daqueles que a compõem. Pio XI, citado por Marcoccia (2011, p. 06), expôs que,

Assim como é totalmente errado tirar dos indivíduos aquilo que eles podem realizar por sua própria iniciativa e trabalho e dar à comunidade, também é uma injustiça designar a uma associação maior e mais alta o que organizações menores e subordinadas podem fazer, porque toda atividade social deve, por sua própria natureza, fornecer ajuda aos membros do grupo social, e nunca destruí-los e absorvê-los.

Atualmente, esse conceito vem sendo usado para determinar as competências entre os poderes públicos de níveis maiores e menores, o que significa que as instituições públicas devem agir de forma mais próxima aos cidadãos e às instâncias locais. Com isso, o Princípio da Subsidiariedade tem como finalidade atribuir melhor as competências aos atores envolvidos e garantir que os poderes do Estado sejam usados de maneira mais eficiente. Para Capelli (2002, p. 52),

Em suma, este princípio prega que as decisões serão tomadas pelo nível político mais baixo, por aqueles que estão mais próximos da situação potencialmente lesiva. Trata-se de um processo de descentralização política e administrativa associado ao fortalecimento do poder local.

Granja e Werner (2006, p. 1103) complementam explicando que tudo o que pode ser solucionado em escala local deve ser assim feito. Para tanto, o ideal é promover adequações legais para permitir que isso aconteça, observando e considerando os interesses nas diferentes esferas envolvidas.

Normalmente, as instâncias mais elevadas estão distantes o bastante para não conhecerem ou não compreenderem a realidade da comunidade local e, por consequência, as suas necessidades. Por outro lado, os atores que estão mais próximos dessa comunidade, como a prefeitura, têm autonomia e poder de decisão até certo ponto, pois esbarram no nível de cima, que é o estadual. Por vezes, as legislações municipais são diferentes das estaduais e nacionais, o que pode se tornar um problema por anos ou décadas para ser resolvido - isso quando é resolvido - o caracterizando os conflitos de poder. Essa burocracia jurídica pode condenar uma determinada comunidade local que precisa do poder mais baixo para melhorar a sua 
qualidade de vida a ficar na dependência de um consenso entre as partes, que pode nunca acontecer. Como argumenta Capelli (2002, p. 51), um grande problema é quando órgãos de níveis de poder diferentes podem legiferar sobre uma mesma atividade, criando uma duplicidade ou multiplicidade de ações políticas.

No Brasil, onde ainda há inúmeras comunidades tradicionais que possuem os mais variados modos de vida e estabelecem relações diferentes com os ecossistemas em que estão inseridas, o Princípio da Subsidiariedade passou a ser praticado com o objetivo de descentralizar o poder do Estado e atribuir mais poder de ação e decisão a populações locais, o que seria a ideia de empoderamento local. Essas populações poderiam usufruir sobremaneira desse empoderamento não somente como garantia de sobrevivência, mas também com uma maneira de manter o dinamismo natural das suas características culturais e de realizar uma exploração do meio com um caráter mais sustentável. Entretanto, a burocracia e a falta de interesse dos organismos públicos para torná-lo real acabam por dificultar o seu sucesso concreto.

Conforme afirmam Granja e Warner (2006, p. 1108),

As instituições do Estado brasileiro estão fundadas no conhecimento por setores, ou seja, se organizam por áreas de atuação, prevalecendo uma cultura fragmentada que dificulta a interação entre especialistas, que acabam criando resistências ao trabalho transdisciplinar.

Todo este complexo emaranhado de poderes, em um país já permeado por inúmeros artifícios burocráticos, como o Brasil, torna mais difícil a manutenção dos diferentes modos de vida, como os tradicionais. As comunidades que se enquadram nesse contexto, sendo elas indígenas ou não indígenas, muitas vezes tentam na Justiça assegurar um direito já garantido pela Constituição Federal, que é o de praticar as suas atividades culturais sem barreiras. Infelizmente, os diversos níveis de poder político podem acabar interferindo de maneira imediata nesse direito e limitando as suas práticas, o que pode ter como consequência o fim dessas comunidades. Nesse sentido, Almeida (2004, p. 61) mostra que a Constituição protege os direitos fundamentais dos indivíduos, mas que tal controle é permeado por limites de atuação da federação para, assim, legitimar a democracia no país. Isso significa que as demais esferas de poder podem atuar e têm isso legalmente garantido, mas, na realidade, é um pouco diferente. Nem sempre os níveis mais baixos de poder conseguem agir, destacando-se as lideranças locais que muitas vezes precisam recorrer ao Judiciário para assegurar os direitos das suas comunidades, mesmo que a lei já determine isso. 


\section{Município de Ilha Comprida: aspectos sociais e físicos}

Ilha Comprida é um município situado no litoral sul do Estado de São Paulo, no baixo Vale do Ribeira, em uma área conhecida como Complexo Estuarino-lagunar de Iguape, Cananéia e Paranaguá. Ilha Comprida se localiza a 24 4428" de latitude sul e $47^{\circ} 32^{\prime} 24^{\prime \prime}$ de longitude oeste e faz divisa com os municípios de Iguape e Cananéia.

\section{VALE DO RIBEIRA}

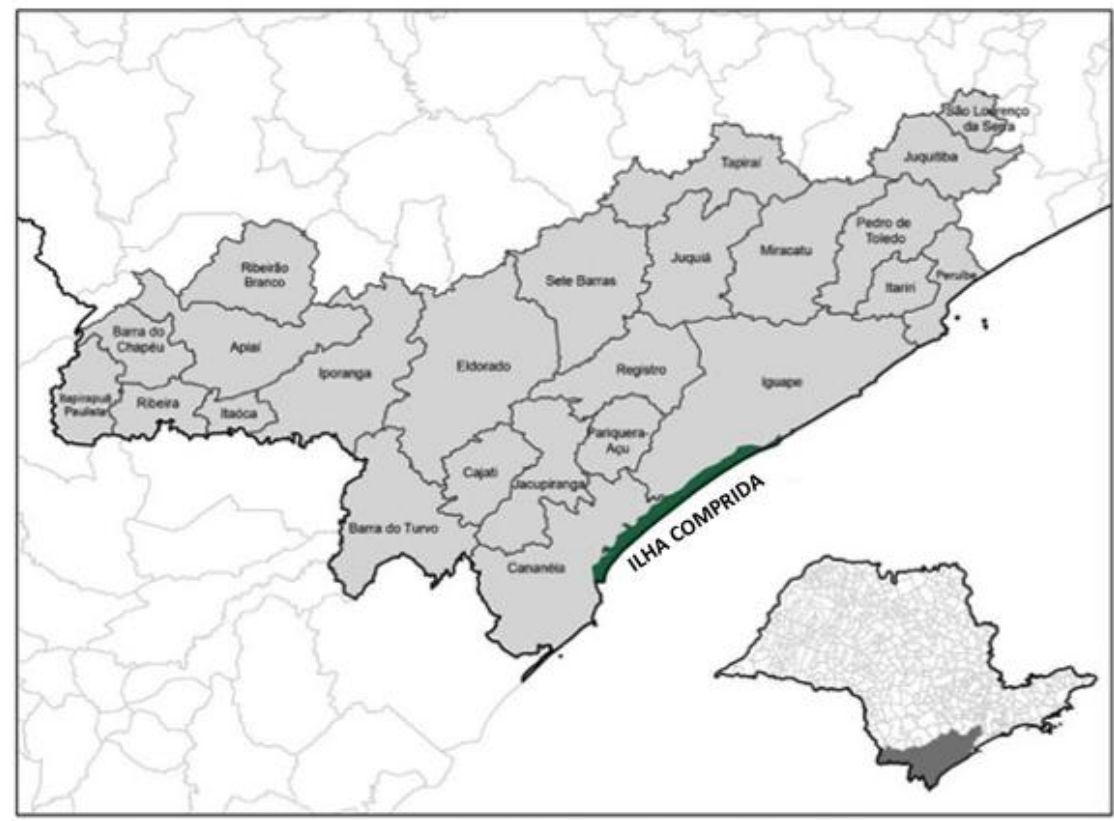

Fonte: Elaboraçăo própria a partir de base de dados georreferenciados,

Divisão Politica 2006 do IBGE. Disponivel em www.ibge.gov.br.

O território de Ilha Comprida foi dividido entre Cananéia e Iguape, em 1938, ficando o primeiro município com a porção sul e o segundo com as porções central e norte. Em 1992, houve a emancipação de Ilha Comprida após plebiscito local e, como deixa claro sua Lei Orgânica, o município não possui área rural, o que não condiz com a realidade do lugar.

A região onde está situada a Ilha Comprida apresenta intensa riqueza ambiental, havendo um mosaico de ecossistemas diferentes - como manguezais, restingas, praias, dunas fixas e móveis, mares interiores, lagoas salobras e outros -, todos associados à Mata Atlântica. Além dessa riqueza biológica, a ilha conta com uma gama de comunidades tradicionais. O município já abrigou mais comunidades 
caiçaras, mas algumas delas acabaram desabitadas em função do rápido processo de urbanização, o que obrigou essas populações a migrarem para outras comunidades ou para áreas urbanas. Oficialmente, conforme declara a Prefeitura Municipal, existem nove comunidades caiçaras - sendo Pedrinhas a maior delas, com uma população de aproximadamente 346 pessoas, segundo informação conseguida no posto de saúde local. Essas comunidades, exceto Pedrinhas, são formadas por algumas poucas famílias. Sítio Arthur, que é um exemplo de comunidade cujos moradores migraram todos para outros lugares, contava com apenas uma família até o final de 2010, tornando-se completamente desabitada a partir de 2011, pois essas pessoas se mudaram para Pedrinhas. Outra comunidade desabitada é Vila Nova, que possui grande importância histórica. Ela foi fundada com o nome de Vila de Nossa Senhora da Conceição da Marinha de Subaúma e sua capela, de 1770, é um testemunho dessa época. Além de Pedrinhas, Sítio Arthur e Vila Nova, as demais comunidades caiçaras são Pontal da Trincheira, Boqueirão Sul - onde fica o porto no qual a balsa faz a ligação entre Ilha Comprida e Cananéia -, Ubatuba - que conta hoje com apenas três famílias -, Juruvaúva - especializada na produção de ostras -, Viaréggio - onde está instalado um projeto experimental sustentável de cultivo de siri -, Ponta da Praia e Araçá, ambas situadas na porção norte da ilha.

Ilha Comprida passa por várias transformações ambientais, muitas vezes potencializadas pelas ações antrópicas. O surgimento da ilha está ligado aos processos de regressão e transgressão marinhas ocorridos no período Quaternário que teve início há 1,8 milhões de anos e segue até os dias atuais - e ao consequente depósito e erosão sedimentares realizados pelo trabalho das águas oceânicas. Guedes (2009, p. 19) afirma que, do momento do seu aparecimento, há pouco mais de 5000 anos AP, toda a ilha sofreu um veloz processo de crescimento longitudinal e transversal. Ele explica que, entre 5000 anos AP e 1900 anos AP, a ilha quase não viu acréscimo transversal e o nível de aumento longitudinal foi baixo, ficando entre 5,2 e $6,9 \mathrm{~m} / \mathrm{a}$. Atualmente, Ilha Comprida possui $74 \mathrm{~km}$ de extensão no sentido Sudoeste - Nordeste e largura máxima de $5 \mathrm{~km}$. Para Becegato (2000, p. 108), a base de Ilha Comprida é composta por sedimentos arenosos pleistocênicos da Formação Cananéia e, sobre ela, segundo Suguio e Martin, citados por Becegato (2007, p. 108), ocorrem sedimentos arenosos holocênicos da Formação Ilha Comprida. Na parte sul da ilha, há um afloramento da Formação Cananéia que é também o ponto mais elevado, conhecido como Morrete, tem $42 \mathrm{~m}$ de altitude.

O relevo de Ilha Comprida é plano, apresentando altitudes que não ultrapassam 9 m em média, com exceção do Morrete (HENRIQUE, 2000, p. 82). Sua vegetação é característica de restinga, manguezal, dunas e praias. Na região conhecida como Juruvaúva, ocorrem dunas estacionárias que chegam a ter entre 20 e 30 metros de altura, sendo o maior ecossistema dessa natureza no estado de São Paulo. Na parte norte da ilha, onde o processo de erosão é acelerado, a área de manguezal está crescendo, conforme informações da Prefeitura Municipal de Ilha Comprida. Já ao sul, está mais presente o processo de deposição sedimentar, fazendo aumentar a 
linha de praia. Segundo Shinji (2009, p. 43), Ilha Comprida sofreu um acréscimo na sua linha de costa a nordeste da ordem de $2800 \mathrm{~m}$ entre os anos de 1882 e 1965, o que significa 35 metros ao ano.

Em 1805, foram iniciadas obras de abertura de um canal entre o rio Ribeira do Iguape, quinto maior rio do estado de São Paulo, e o Mar Pequeno, para encurtar o trajeto e o tempo de viagem das embarcações da época até o porto de Iguape. Em 1852, as obras foram terminadas e o canal, conhecido como Valo Grande, inaugurado, medindo, naquele momento, 4,40 m de largura e $3 \mathrm{~km}$ de extensão. No decorrer do tempo, o rio Ribeira do Iguape foi se adaptando às novas características do lugar e, atualmente, a abertura apresenta mais de $300 \mathrm{~m}$ de largura, o que mostra que boa parte das suas águas passou a correr no Valo Grande e abandonou a sua foz original (HENRIQUE \& MENDES, 2001, p. 205).

Esse alargamento do Valo Grande transformou não somente a paisagem do lugar onde ele foi aberto, mas também as características do Mar Pequeno, que teve sua salinidade alterada, novas espécies de animais e plantas e outras tantas que desapareceram por conta das transformações. Para Henrique (2000, p. 50), esse canal é um problema ambiental até a atualidade e atinge toda a dinâmica da paisagem na região, seja sob a ótica biológica ou geomorfológica.

Da mesma maneira, ocorreu uma mudança na configuração urbana, especialmente de Iguape, que teve o bairro original do Roccio inundado com o alargamento do canal. Mas também houve a intensificação da erosão na parte norte de Ilha Comprida, o incremento da poluição nas águas do Mar Pequeno vinda das áreas mais altas do Vale do Ribeira e, entre outras mudanças, uma adaptação forçada dos pescadores caiçaras da região, que nem todos conseguiram, tendo, como consequência, que conviver com a pobreza e a desorganização social das suas comunidades. Um exemplo desse processo é o da comunidade caiçara de Sítio Arthur, que se tornou oficialmente despovoada a partir de 2011. Seus moradores se mudaram para a comunidade de Pedrinhas em busca de melhores condições de vida, já que a pesca e a coleta de ostras - atividades comuns nessa localidade em anos anteriores - sofreram um decréscimo por conta das transformações ambientais ocorridas no seu entorno.

No primeiro semestre de 2011, o governo de São Paulo, através da Secretaria de Saneamento e Recursos Hídricos, concluiu uma larga pesquisa sobre o Valo Grande, que foi apresentada à população dos municípios de Ilha Comprida e Iguape em maio daquele ano. Os habitantes de ambos os municípios foram convocados a participar de reuniões públicas e tomar conhecimento do estudo para, a partir daí, votar pelo fechamento ou permanência da abertura do Valo Grande. Como a maioria escolheu o seu fechamento, as obras foram iniciadas em junho do mesmo ano. Esse fechamento deveria acontecer de forma paulatina e monitorada para a verificação do comportamento do ambiente diante dessas novas modificações. Segundo o relatório da pesquisa, as comportas deveriam ser instaladas antes do verão de 2011, assim como as vias de acesso até a barragem, dando início também aos processos de 
monitoramento e ajustes necessários diante do andamento do projeto. Segundo o jornal digital O Vale do Ribeira (2011), em setembro de 2011 uma juíza da $2^{\text {a }}$ Vara Judicial de Iguape determinou pelo fechamento total das comportas do Valo Grande e adoção de medidas mitigadoras na tentativa de remediar os impactos ambientais.

\section{APA de llha Comprida}

Uma APA (Área de Proteção Ambiental), a partir da afirmação de Silva, citado por Araripe (2008), é uma unidade de conservação determinada a proteger e conservar a qualidade ambiental e todos os ecossistemas que estão inseridos naquela área, bem como suas populações tradicionais. Araripe (2008) complementa que o SNUC (Sistema Nacional de Unidades de Conservação) deixa claro que uma APA possui limitações quanto ao uso e exploração dos seus recursos naturais e, para que isso aconteça, é necessário um plano de manejo para garantir a capacidade de suporte da unidade de conservação.

Ilha Comprida, mesmo antes da sua emancipação política, foi inteiramente transformada em Área de Proteção Ambiental, que é uma unidade de conservação gerida pelo governo do Estado de São Paulo. Isso aconteceu em 1987, conforme o Decreto $\mathrm{n}^{\circ}$ 26.881, de 11 de março, que estabeleceu uma ZVS (Zona de Vida Silvestre), sendo regulamentada no ano de 1989 pelo Decreto $n^{\circ} 30.817$, de 30 de novembro, que definiu uma ARIE (Área de Relevante Interesse Ecológico). O que justifica a condição da ilha como APA, segundo o governo estadual de São Paulo, é a importância do Complexo Estuarino-lagunar de Iguape, Cananéia e Paranaguá, onde se insere Ilha Comprida. É destacado seu papel como barreira protetora do Mar Pequeno em relação às interferências diretas do oceano, os ecossistemas variados existentes em seu território, o potencial para a prática da aquacultura no Mar Pequeno e a existência de comunidades de pescadores tradicionais, que devem ter o seu modo de vida garantido. De acordo com Carvalho (1999, p. 135), a criação da Unidade de Conservação em Ilha Comprida é fundamentada em alguns fatores preponderantes, como a existência de variados ecossistemas na região, muitas espécies de animais e plantas e, ainda, pela presença de comunidades de pescadores tradicionais ao longo da ilha.

Magalhães (2003, p. 117) explica que a APA de Ilha Comprida ocupa a totalidade do município de mesmo nome, abrangendo então uma área de $192 \mathrm{~km}^{2}$. Ela complementa, elencando que há cerca de trinta espécies de aves marinhas migratórias na ilha, condição que coloca Ilha Comprida como a quarta maior em diversidade dessas aves na América Latina. Além das aves, a autora lembra que a costa da ilha é a porção do litoral brasileiro na qual há maior incidência do lobomarinho subantártico, sem contar as diversas espécies de baleia e golfinho que usam a região para acasalar e como o nascedouro dos seus filhotes. Esses e outros fatores justificam a criação de uma unidade de conservação em Ilha Comprida. 
A partir das condições jurídicas da APA, expostas nas propostas de zoneamento ambiental do Estado de São Paulo em 1992, o município ganhou no instante da formalização da Unidade de Conservação o seguinte zoneamento:

$\checkmark$ Zonas urbanizadas e passíveis de urbanização: onde seria permitido o crescimento urbano da ilha e, na ocasião da criação da APA, se encontravam bastante degradadas. Os novos loteamentos passariam a ter que respeitar as regras impostas para a construção civil.

$\checkmark$ Zonas controladas: onde ocorrem ecossistemas de transição entre as praias e o interior da ilha, que estavam medianamente degradadas quando da sua criação. Nesse setor, alguns lotes foram vendidos ilegalmente em área de preservação e a Prefeitura Municipal deveria analisar a situação de cada um deles para tomar as medidas necessárias.

$\checkmark$ Zona de vida silvestre: formada por manguezais, florestas de restinga e drenagem de diferentes tipos que até então se encontravam pouco degradados. Verificou-se a venda de lotes de forma irregular e a construção de casas em áreas proibidas, cabendo também à Prefeitura analisar a situação.

$\checkmark$ Zona de proteção especial: localizada no extremo norte da ilha, onde se encontra o maior adensamento urbano, é caracterizada pela intensa erosão e mudança rápida da linha de praia. Assim como na maioria das demais zonas, essa também teve vários lotes criados e vendidos, além de novas construções feitas, todas sob a responsabilidade da Prefeitura de analisar e encontrar uma solução aos problemas apresentados.

Durante o processo de criação da APA, a maior parte da população caiçara foi a favor, pois queria que os loteamentos surgidos de maneira desordenada não fossem mais permitidos, assim como a grilagem - bastante comum na ilha. Por outro lado, essa mesma população não tinha conhecimento daquilo que seria permitido e proibido a partir do momento que a unidade fosse legalmente oficializada. Para os caiçaras, eles iriam poder manter suas atividades sem quaisquer alterações, no entanto muitos deles perceberam com o tempo que não havia um afinamento entre as normas da APA e aquilo que eles julgam ser preservação ambiental (CARVALHO, 1999, p. 136).

Historicamente, Ilha Comprida viu os primeiros loteamentos aparecerem na década de 1950, mas tal fenômeno foi agravado na década de 1970, quando inúmeros lotes foram vendidos com autorização das prefeituras de Iguape e Cananéia. Isso contribuiu sobremaneira para o aumento acelerado da degradação ambiental na região. $\mathrm{O}$ fato de Ilha Comprida nesse momento estar dividida entre os municípios de Cananéia e Iguape tornou a situação ainda mais grave, pois ambas as prefeituras não perceberam que a prática fazia com que a paisagem da ilha fosse profundamente transformada em toda a sua extensão e, portanto, as medidas tomadas por cada uma delas se baseavam em interesses políticos isolados. Tal 
situação acabou por contribuir para a busca de uma alternativa para a Ilha Comprida, cuja única encontrada foi a criação de uma APA.

\section{A APA de llha Comprida e o Princípio de Subsidiariedade}

A manutenção da APA em uma região com tamanha riqueza biológica e cultural se faz necessária, mas as características geológicas e geomorfológicas de Ilha Comprida a tornam um ambiente em constante mutação, o que nem sempre consegue ser contemplado pela legislação dessa Unidade de Conservação.

Segundo a legislação que regulamenta a APA de Ilha Comprida, elucidada por Oliveira (2002, p. 20), há algumas diretrizes básicas e importantes, como garantir a manutenção, a preservação e a conservação dos ecossistemas da ilha, do patrimônio cultural e arqueológico, assim como das áreas de sambaquis. Da mesma forma, a legislação enumera os núcleos de pescadores tradicionais caiçaras e estabelece a necessidade de assegurar a eles os meios de manter a sua cultura de forma dinâmica, o exercício das suas atividades econômicas e a maneira como ocupam historicamente o território. Apesar de constar na lei a garantia aos caiçaras de continuarem exercendo o seu modo de vida à sua maneira, a prática mostra exatamente o contrário. Com o passar dos anos, o número de pescadores tradicionais caiu substancialmente na ilha em função da pobreza, do crescimento desordenado da área urbana e de uma série de proibições legais que os impediram de sobreviver dignamente.

A legislação estadual acaba não abarcando de forma correta o modo de vida caiçara e a prefeitura fica limitada em garantir o que diz a APA, já que possui pouco poder de interferência nesse processo jurídico. Muitas práticas caiçaras acabaram sendo forçadas a mudar diante da transformação de Ilha Comprida em APA, como:

$\checkmark$ Barco de Pesca e remos: eram feitos de madeira de árvores típicas da região e duravam várias gerações. Com a legislação da APA, a derrubada de árvores para essa finalidade se tornou proibida e os caiçaras passaram a utilizar barcos de alumínio, fibra de vidro ou de outros materiais e os remos foram substituídos pelo motor. Segundo relato dos caiçaras, esses barcos e o motor possuem durabilidade menor, requerendo manutenção constantemente, o que demanda maior investimento financeiro.

$\checkmark$ Casas caiçaras: feitas de madeira, passaram a ser construídas com cimento e tijolo. Isso demanda mão de obra especializada de pedreiros e fez com que um ritual típico dessa população tivesse fim, os mutirões, quando os caiçaras se reuniam para construir a casa de algum deles e eram pagos com um baile ao final da construção, chamado de fandango. Com a APA, o fandango já não é mais praticado e a forma de pagamento passou a ser o dinheiro.

$\checkmark$ Organização espacial das casas caiçaras: antes da APA, os caiçaras construíam as casas respeitando suas regras sociais, deixando espaços abertos entre uma e outra 
para permitir a livre circulação das pessoas e facilitar o acesso à casa dos vizinhos. Também era delimitado e respeitado um espaço maior destinado aos encontros sociais, onde conversavam, combinavam mutirões e casamentos, compartilhavam problemas familiares e tinham, dessa forma, um lugar de lazer e socialização. Depois da APA, adotou-se uma nova disposição espacial a partir de metragens de loteamentos que iam de encontro a esse modo de vida tradicional. Muros passaram a ser construídos e, assim, as vias de circulação e áreas de encontro da comunidade desapareceram.

$\checkmark$ Outras atividades remuneradas além da pesca: basicamente, o pequeno comércio local e a venda de pescados aos moradores das próprias comunidades ou a turistas. Com a proibição da pesca durante uma parte do ano, muitos pescadores precisaram buscar alternativas para garantir a própria sobrevivência e de sua família. Muitos se tornaram caseiros, faxineiros, trabalhadores da construção civil local ou migraram para outras localidades da ilha ou mesmo para outros municípios. Parte dos caiçaras mais jovens não quer se tornar pescador, justamente por ver as dificuldades enfrentadas pelas famílias com essa atividade. Dessa forma, as práticas pesqueiras, antes ensinadas às gerações seguintes, começaram a desaparecer.

De acordo com Manoel de Oliveira Lisboa, mais conhecido como Seu Nezinho, morador de Pedrinhas e vice-prefeito do município de Ilha Comprida na gestão entre 2009 e 2012, há hoje cerca de 150 caiçaras autênticos na ilha, aqueles que ainda mantêm o seu modo de vida tradicional e se reconhecem como caiçaras. Segundo Diegues (2004, p. 275),

A tradição caiçara é entendida como um conjunto de valores, de visão de mundo e de simbologias, de tecnologias patrimoniais, de relações sociais marcadas pela reciprocidade, de saberes associados ao tempo da natureza, de dança e música associadas à periodicidade das atividades de terra e de mar, de ligações afetivas fortes ao sítio e à praia. Essa tradição, herdada dos antepassados, é constantemente reatualizada e transmitida às novas gerações pela oralidade. É por meio da tradição que são usadas as categorias de tempo e espaço e é mediante essas últimas que são interpretados os fenômenos naturais.

Em 2007, a direção da APA revogou a licença que os caiçaras tinham para fazer a extração da samambaia, com a alegação de que essa atividade degrada o meio e pode levar a espécie à extinção. Mesmo após uma grande pesquisa de mestrado realizada por Vivian Gladys de Oliveira (2002) pela Universidade de São Paulo sobre o manejo de samambaias, que provou que a extração dessa planta feita pelos caiçaras não provoca a extinção da espécie e muito menos degrada o meio, a licença foi revogada e essa atividade, que era praticada há décadas, convertida em crime. Alguns caiçaras passaram a retirar o musgo de áreas lodosas como forma alternativa 
de sustento, mesmo tendo a clareza de que esta é uma atividade que provoca impacto ambiental negativo, mas que não é ilegal - coisa que a torna, assim, uma nova fonte de renda para eles. A Prefeitura passou a lutar desde então para rever essa decisão, o que não conseguiu durante anos. Isso pode ser explicado a partir da ótica do Princípio da Subsidiariedade, que a coloca em um nível baixo de poder, fato pelo qual precisa se submeter aos níveis superiores, que, na ocasião, são a favor da decisão tomada. A gestão da APA exigia que novos estudos fossem feitos ou então a proibição não seria retirada, mas isso vai de encontro ao colocado pela regulamentação da APA. Da mesma forma, os caiçaras, que se organizaram melhor, também tentaram estabelecer um diálogo com o objetivo de que seu consenso e participação fossem levados em consideração no momento de tomada dessas decisões.

No ano de 2011, houve mudança na gestão da APA e uma das primeiras medidas tomadas pelo novo administrador da unidade de conservação foi a liberação da licença de exploração da samambaia, tornando essa atividade novamente permitida entre os caiçaras. Apesar da conquista, parte dessa população ficou alguns anos sem poder sobreviver da forma como vinha fazendo há bastante tempo e não mais voltou a extrair a samambaia, o que prova como a legislação praticada de cima para baixo pode interferir negativamente na vida do cidadão. Aqueles que assinam as leis são justamente os mesmos que desconhecem a realidade local e, em contrapartida, as instituições daquele lugar, que teriam mais condições de tomar as decisões acertadas, não têm poder para isso ou o têm bastante limitado.

Em 2011, como parte da política da nova gestão da APA, um novo plano de manejo foi proposto para Ilha Comprida com a participação de toda a população do município, incluindo as comunidades caiçaras. Várias reuniões públicas ocorreram entre junho e julho de 2011, com a convocação dos habitantes, tendo como objetivo efetivar essa participação comunitária, já que foi um momento para que os representantes de instâncias estaduais pudessem ouvir as necessidades da população local e levar sugestões e reclamações que ela gostaria que fossem contempladas no plano. Após o fim de todos os levantamentos feitos nessas reuniões, o mapeamento da ilha e da identificação das características socioculturais do município será produzido um relatório para, posteriormente, ser ajustado e aprovado pelo Conselho da APA, pela Fundação Florestal e pelo Conselho Superior de Meio Ambiente (CONSEMA).

Conforme elucida Santos (2012, p. 115), os moradores da comunidade de Pedrinhas enxergam a implantação da APA como uma medida com pontos positivos e negativos. Para eles, a APA é importante para preservar os diferentes ecossistemas da ilha, dos quais os pescadores dependem diretamente. Ela também freou a construção indiscriminada de casas e contribuiu para a volta dos guarás, aves de cor avermelhada que tinham desaparecido da ilha, mas voltaram a circular pelo Mar Pequeno. Dentre as desvantagens da APA, eles temem que suas tradições desapareçam em definitivo por conta das várias proibições determinadas pela 
legislação e questionam o fato de sua pesca artesanal ter sido profundamente alterada quando o mesmo não aconteceu com a pesca em escala industrial, que promove impactos ambientais negativos muito mais graves. Apesar dos benefícios trazidos pela APA, eles afirmam que os prejuízos são muito maiores e que, portanto, não valeria o sacrifício dessas pessoas.

Diante de tantos problemas, é necessário rever a legislação da APA para atualizála e torná-la mais próxima da realidade de Ilha Comprida. Assim, talvez as tomadas de decisão aconteçam de forma menos burocrática e causem menos conflitos de interesses.

\section{Considerações Finais}

O poder representado pelo Estado deve garantir a qualidade de vida das diversas populações e permitir a manutenção dos seus diferentes modos de vida, executados muitas vezes de forma tradicional. Na prática, essa realidade está distante de acontecer, uma vez que esse mesmo Estado cria leis e categorias de governo que dificultam o exercício pleno dos direitos dos seus cidadãos.

Tais categorias políticas têm como intenção principal descentralizar o poder e atender melhor às necessidades locais, especialmente em um país com a dimensão territorial do Brasil. À medida que a descentralização acontece, vem junto com ela uma sobreposição política que reduz a ação das instituições governamentais. Portanto, o instrumento que deveria desburocratizar as decisões políticas contribui para que ela aconteça e, por vezes, de maneira ainda maior.

Em Ilha Comprida, situada em uma região conhecida pela sua pobreza econômica em relação às demais áreas do estado de São Paulo, a situação das esferas governamentais tem complicadores, a existência de uma unidade de conservação e o fato de ter sido elevado recentemente a município.

Sua emancipação trouxe heranças de um território pertencente a dois municípios diferentes e com formas de governo também distintas, o que tornou essa integralização política delicada no momento de ter apenas uma municipalidade. Além disso, a APA, que é administrada pelo governo estadual e abrange toda a área municipal, produz restrições de atuação à prefeitura, aquela que está mais próxima da realidade local. Juntamente com ela, há ainda as lideranças caiçaras, que perderam parte da sua influência por conta desse complexo sistema de leis estaduais e municipais que nem sempre convergem. Ao contrário do que determina a APA, o empoderamento dessas lideranças praticamente desapareceu. A situação de heterogeneidade das forças políticas deixou de assegurar o poder de voz da população local e, portanto, a sua participação nas tomadas de decisão. Isso deflagrou uma cruel sequela, pois tudo o que é decidido influi diretamente em suas vidas e pode ser uma maneira de melhorá-las ou extingui-las de uma vez. 
A APA de Ilha Comprida deve dar condições para que as comunidades de pescadores tradicionais possam manter o seu modo de vida. Infelizmente, isso não vem acontecendo e a falta de consenso entre as esferas estadual e municipal contribui largamente para a manutenção dessa situação. Enquanto as decisões e resoluções de problemas não são realizadas com harmonia entre a Prefeitura Municipal e o Estado de São Paulo, os principais afetados por esses impasses e burocracias são os moradores de Ilha Comprida, que veem seus lotes se tornarem ilegais, a realização de um planejamento urbano condizente com os aspectos físicos e socioeconômicos do município ficar cada vez mais distante, as manifestações culturais caiçaras virarem memória e mais obstáculos surgirem com essa falta de consenso político.

A APA é de extrema importância e Ilha Comprida precisa de instrumentos políticos de preservação da sua fauna, flora e comunidades tradicionais caiçaras, mas isso tem que acontecer de forma que os seus atores coexistam sem tantos obstáculos e com uma participação verdadeiramente efetiva da população local para que, dessa forma, as necessidades e características do município sejam o ponto central das discussões, e não os interesses individuais ou de pequenos grupos. O fato de Ilha Comprida ter se emancipado recentemente é um complicador a mais, pois a sua força política ainda não está definida, além de haver muitas leis municipais que precisam ser alteradas ou ainda organizadas e aprovadas. O município está se firmando, compondo-se politicamente e, portanto, talvez haja certo despreparo para enfrentar alguns desafios e conseguir resolver parte dos problemas criados.

\section{Bibliografia}

ALMEIDA, Caroline C. de. (2004) A cláusula de subsidiariedade na arguição de descumprimento de preceito fundamental. Revista da Fundação da Escola Superior do Ministério Público do Distrito Federal e Territórios, Brasília, ano 12, v. 23. pp. $60-84$.

ARARIPE, Carlos A.; FIGUEIREDO, Paulo J. M.; DEUS, Adilson S. de. (2008) Zoneamento de APA. Preocupação com a capacidade de suporte ou garantia da ação antrópica capitalista? O caso de Ilha Comprida, litoral sul de São Paulo. In: Encontro Nacional da Anppas, 6, Brasília.

BECEGATO, João L.; SUGUIO, Kenitiro. (2007) Impacto ambiental antrópico na APA (Área de Proteção Ambiental) de Ilha Comprida (SP): da pré-história à atualidade. Revista UnG-Geociências, Guarulhos, v. 6, nº 1. pp. 107 - 117.

CAPELLI, Sílvia. (2002) Gestão ambiental no Brasil: sistema nacional de meio ambiente - do formal à realidade. In: Conferência Internacional sobre Aplicação e Cumprimento da Normativa Ambiental na América Latina, 1, Buenos Aires.

CARVALHO, Maria C. P. de. (1999) Histórias da ilha: temporalidade e apropriação do espaço na Ilha Comprida. Campinas. 158 f. Dissertação (Mestrado 
em Antropologia) - Instituto de Filosofia e Ciências Humanas, Universidade Estadual de Campinas. Campinas.

DIEGUES, Antônio C. (Org.). (2004) Enciclopédia Caiçara - o olhar do pesquisador, volume 1. São Paulo: Hucitec: Nupaub/CEC.

GRANJA, Sandra I. B.; WARNER, Jeroen. (2006) A hidropolítica e o federalismo: possibilidades de construção da subsidiariedade na gestão das águas do Brasil. Revista de Administração Pública, Rio de Janeiro, no 40 (6), nov./dez. pp. 1097 1121.

GUEDES, Carlos C. F.. (2009) Evolução quaternária da Ilha Comprida, estado de São Paulo. 133 f. Dissertação (Mestrado em Geoquímica e Geotectônica) - Instituto de Geociências, Universidade de São Paulo. São Paulo.

HENRIQUE, Wendel. (2000) Zoneamento ambiental: uma abordagem geomorfológica. 133 f. Dissertação (Mestrado em Geografia) - Instituto de Geociências e Ciências Exatas, Universidade Estadual Paulista. Rio Claro.

HENRIQUE, Wendel; MENDES, Iandara A. (2001) Zoneamento ambiental em áreas costeiras: uma abordagem gemorfológica. In: GERARDI, Lúcia H. de O.; MENDES, Iandara A. (Org.). Teoria, técnica, espaços e atividades: temas de geografia contemporânea. Rio Claro: Programa de Pós-graduação em Geografia UNESP; Associação de Geografia Teorética - AGETEO. pp. 199 - 222.

IBGE. Divisão Política: Vale do Ribeira. Disponível em: http://www.scielo.br/scielo.php?script=sci_arttext\&pid=S1679-

39512011000300005. Acessado em: 10 abr. 2015.

MAGALHÃES, Nícia W. (2003) Descubra o lagamar. São Paulo: Terragraph.

MARCOCCIA, Rafael (2011) M. Subsidiariedade e modelos econômicos. Revista Brasileira da História das Religiões, Maringá, nº 9. pp. 01 - 10, jan.

OLIVEIRA, Vivian G. de. (2002) Educação ambiental e manejo de recursos naturais em área de proteção ambiental: o caso dos extratores de samambaias da Ilha Comprida - SP. 117 f. Dissertação (Mestrado em Recursos Florestais, com opção em Conservação de Ecossistemas Florestais) - Universidade de São Paulo. Piracicaba.

O VALE DO RIBEIRA. Disponível em: http://www.ovaledoribeira.com.br. Acessado em: 6 mar. 2013.

PREFEITURA MUNICIPAL DE ILHA COMPRIDA. Disponível em: http://www.ilhacomprida.sp.gov.br/home/. Acessado em: 7 mar. 2013.

SANTOS, Valesca C. dos. (2012) Alterações ambientais no município de Ilha Comprida, SP: estudo de caso da comunidade caiçara do bairro de Pedrinhas. $175 \mathrm{f}$. Dissertação (Mestrado em Geografia) - Universidade Estadual de Campinas. Campinas.

SÃO PAULO (Estado). (1992) Coordenadoria de Planejamento Ambiental. Áreas de proteção ambiental do estado de São Paulo - APAs - Propostas de zoneamento ambiental. Secretaria do Meio Ambiente, Coordenadoria de Planejamento Ambiental. São Paulo. 
SÃO PAULO (Estado). (1990) Decreto n ${ }^{\circ}$ 30.817, de 30 de novembro de 1989. Regulamenta a Área de Proteção Ambiental da Ilha Comprida criada pelo Decreto 26.881, de 11 de março de 1987, que declara a mesma APA com interesse Especial e cria, em seu território, Reservas Ecológicas e Áreas de Relevante Interessante Ecológico. Diário Oficial do Estado de São Paulo. Poder Executivo, v. 100, n 21, 21 fev. São Paulo.

SECRETARIA DE SANEAMENTO E RECURSOS HÍDRICOS, DEPARTAMENTO DE ÁGUAS E ENERGIA ELÉTRICA. (2011) Sistematização de base de dados ambientais do Complexo Estuarino-Lagunar de Iguape-Cananéia visando subsidiar a regra operativa da barragem do Valo Grande (Iguape), maio. 120 p. Relatório final.

SHINJI, Fernando K. (2009) Avaliação das mudanças na linha de costa na foz do rio Ribeira do Iguape / desembocadura lagunar da Barra do Icapara (litoral sul de São Paulo - Brasil) utilizando dados do Landsat MSS, Tm e ETM+. Investigaciones Geográficas (Mx), México, no 68. pp. 41 - 49. 